\title{
Krankheit und Tod des Komponisten Johannes Brahms
}

\author{
Von JuraJ Körbler, Zagreb
}

Johannes Brahms war am 7. Mai 1833 in Hamburg geboren im Armenviertel, im sogenannten «Specksgang», welcher im Jahre 1832 auch als «Ehebrechergang » bezeichnet wird, wegen der dortigen Dirnenwohnungen. Sein Vater, JohanN Jаков Braнms, war Straßenmusikant und stammte aus Heide in NorderDithmarschen im Holsteinischen.

Der als Komponist bereits bekannte und gefeierte Johannes Brahms verweilte in Ischl, als ihn am 20. Mai 1896 die Nachricht vom Tode Clara Schumanns erreichte, welche einem erneuten Schlaganfall erlegen war. In kaum einer Stunde machte er sich reisefertig und bestieg den Expreßzug in der Richtung Frankfurt. In Wels versäumte er den Wagenwechsel und mußte mit Personenzügen über Passau weiterfahren. Nach einer durchfahrenen Nach $九$ kommt er in Frankfurt an und erfährt dort, daß die Beerdigung in Bonn stattfinden wird. Er nimmt den Kölner Nachtzug dorthin und kommt am Pfingstsonntag zu dem Schluß der Begräbniszeremonie.

Von dieser anstrengenden, vierzigstündigen Reise nach Ischl zurückgekehrt, war er immer noch seelisch stark ergriffen, körperlich jedoch anscheinend ganz wohl, denn er äußert sich zu seinen Freunden: «Das soll mir einmal ein jüngerer nachmachen. » Kurze Zeit danach fuhr er nach Wien, wo der mit ihm befreundete Rechtsanwalt Dr. Richard Fellinger silberne Hochzeit feierte. Dort wurde eine Veränderung in seinem Aussehen bemerkt, man ließ ihn jedoch nichts davon merken.

Seine Freunde in Ischl sind bestürzt und besorgt wegen seiner zitronengelben Gesichtsfarbe und weil sie sich jetzt entsinnen, daß ihnen schon im Frühjahr manchmal eine vorübergehende, bräunlich-gelbe Hautfärbung bei ihm aufgefallen war. Am 7. Juli 1896 macht Richard Heuberger als erster den Kranken auf sein Leiden aufmerksam, indem er ihn fragt, ob er sich denn ganz wohl fühle. Als Grund für seine Frage gibt er die beobachtete gelbliche Gesichtsfarbe und die Trübung des Weißen im Auge an. Der verwunderte BraHms dankt und verspricht, dem Rat, einen Arzt zu konsultieren, folgen zu wollen.

Der erste Arzt, der den Kranken untersuchte, war Dr. Hertzka, Direktor einer Wasserheilanstalt in Ischl. Er sprach zum Kranken nur von einer Gelbsucht und verbot den Genuß von stark gewürzten Speisen. Außerdem hat er eine Trinkkur in Karlsbad vorgeschlagen, mit der jedoch BRAHMs nicht einverstanden war. Brahms war beruhigt und benachrichtigte seinen Freund Heuberger, es sei bei ihm nur eine kleine «bürgerliche Gelbsucht», die mit einer Diät und einer Badekur rasch wegzukriegen sei. Der Arzt hat dem Kranken verschwiegen, daß er einen 
vollständigen Verschluß der Gallengänge und eine heftige Anschwellung der Leber gefunden hatte.

Von der bei Brahms festgestellten Erkrankung hat Dr. Hertzka den in Rinnbach bei Ebensee über Sommer wohnenden bekannten Internisten LEOPOLD Schrötter, Ritter von Kristelli (1837-1908), verständigt, welcher damals Vorstand der dritten medizinischen Klinik zu Wien und Professor an der Universität war. Von Heuberger veranlaßt, hat Schrötter einen Krankenbesuch am Kaiserlichen Hof in Ischl fingiert, um Braнms zu untersuchen. Schrötter hat BraHms beruhigt: Es bestehe zwar eine Gelbsucht, ein unangenehmes Unwohlsein, nichts weiter von Belang. Karlsbad könne dabei nicht schaden, aber es müsse nicht sein, nur eine Diät müsse gehalten werden. Als SchrötTER so «vorüberkam», erhielt Heuberger von Brahms am 2. August eine Mitteilung, «daß Dr. Schrötter eben da war ... und den Ausspruch getan hat: nach Karlsbad zu gehen oder überhaupt eine stärkere Kur zu gebrauchen, läge nicht der geringste Anlaß vor». Zu Heuberger, der ihn am Bahnhof einholte, sagte Schrötter: «Armer Kerl! Karlsbad hat keinen Sinn - wo der sein Geld ausgibt, ist völlig gleichgültig.»

Zunächst trank BRAHMs in Ischl vier Wochen durch Karlsbader Wasser ohne jeglichen Erfolg. Danach ließ er sich doch nach Karlsbad schicken, welches er seinerzeit, am Krankenlager seines Vaters sitzend, «beredet» hatte. Der Vater von Brahms ist am 11. Februar 1872 gestorben an einem Leberleiden, welches ein Krebs gewesen sein mag.

Am 3. September in der Früh ist Brahms in Karlsbad angekommen. Auf der Nachtfahrt hat ihn sein Freund Dr. Fellinger begleitet. Gleich am Tag seiner Ankunft hat Brahms den ihm empfohlenen Arzt aufgesucht. Dieser hat eine Leberentartung und eine Entzündung der Gallenwege festgestellt und den $\mathrm{Zu}$ stand als überaus ernst bezeichnet. Der ahnungslose BraHms schreibt weiter von seiner lästigen «bürgerlichen Gelbsucht».

Am 13. September reiste Professor Th. W. Engelmann aus Utrecht nach Österreich «aus Berufsgründen» und machte den «Umweg» über Karlsbad, weil er BRAHMs unauffällig untersuchen wollte. In einem Brief aus Utrecht vom 29. September empfahl er eine kräftigere Diät.

Kränker und matter als er gegangen war, ist BRAHMs am 2. Oktober abends nach Wien zurückgekehrt. Bald danach hat ihn sein Biograph Sреснт gesehen: Er war kaum wiederzuerkennen. Die Gesichtsfarbe war vom Gelben ins Bräunliche und Schwärzliche übergegangen, das Weiße des Auges schimmerte zitronengelb, das Haupt sank müde vornüber, der Blick war erloschen. Dazu kamen Unterleibsbeschwerden und ein beständiges Jucken. BRAнмs beobachtet mit Mißtrauen den Eindruck, den er auf andere Menschen macht. Engelmann hat ihn zu seinem Schwiegersohn, dem Chirurgen Professor Narath, geschickt, der ihn «so unbefangen als gründlich» untersuchte und fand, «daß trotz der Langwierigkeit der 
Sache kein Grund vorläge, an eine irreparable Störung zu denken», jedoch hat er die mögliche Notwendigkeit einer operativen Nachhilfe angedeutet.

In Wien wurde Brahms von Dr. Fröschl, dem Hausarzt Fellingers, und von Dr. Tilg behandelt. In seinen Notizen vermerkt Brahms 24 elektrische und 18 Jodbäder. Am 4. Januar 1897 bemerkt er darunter : «bezahlt 120 fl.»

Im Februar kam es zu einem Schlaganfall, was der Kranke als störenden «Gesichts-Rheumatismus» deutet. Am 26. März legte sich der Kranke zu Bett und war meist apathisch. In einem Brief vom 30. März 1897 hat ENGELmanN einen Versuch mit Pankreas (frisch von Rind, in Oblaten oder fein gehackt, täglich 40 bis $50 \mathrm{~g}$ ) empfohlen, ebenso Einspritzungen mit orchitischem Extrakt (Liquide orchitique Sequardine).

In der letzten Zeit hat die Behandlung des Kranken Dr. Josef Breuer übernommen. Zunächst war er in der Diagnose nicht sicher : Er dachte an eine Leberzirrhose oder Leberkrebs, jedoch nach kurzer Zeit entschied er sich für die Diagnose: Krebs.

Bei dem Kranken wechseln wache Momente mit Schwächeanfällen ab, auch Darmblutungen haben sich eingestellt, aber der Kranke leidet keine Schmerzen. Am 2. April tritt die Agonie ein. Professor Hermann Nothnagel wurde zum Konsilium berufen, er kann jedoch nichts ausrichten. In der Nacht vom 2. zum 3. April wacht am Krankenbett der junge Dr. Robert Breuer, der Sohn des behandelnden Arztes, abwechselnd mit Frau TruxA, welche heimlich die Kleider ihres Hausgenossen enger genäht hat, um ihn glauben zu machen, er sei während der Krankheit wieder stärker geworden. Gegen Mitternacht erwacht der Sterbende und klagt über eine schmerzhafte Spannung im Leib. Er bekommt eine Morphiuminjektion. Gegen 4. Uhr in der Früh trinkt er ein Glas Rheinwein und spricht seine letzten Worte: «Ach, das schmeckt schön.»

Brahms starb am 3. April 1897 um 8.30 Uhr in Wien. Das Begräbnis fand am Dienstag, dem 6. April, nachmittags statt. Nach den Angaben seines Biographen Specht ist die Diagnose Leberkrebs durch die Sektion bestätigt worden, jedoch das Sektionsprotokoll aufzufinden ist mir bei Nachforschungen in Wien nicht gelungen.

\section{Literatur}
A. Ehrmann, Johannes Brahms, Leipzig 1933.
R. Heuberger, Musikalische Skizzen, Leipzig 1901.
R. SPECHT, Johannes Brahms, Hellerau 1928. 